\title{
Taurochenodeoxycholic Acid Suppresses NF-kB Activation and Related Cytokines Expression in Peritoneal Macrophages from Adjuvant Arthritis Rat
}

\author{
Wei Mao ${ }^{\oplus}$, Mingqiang Liu ${ }^{\circledR}$, Hong Guan ${ }^{\odot}$, Bo Liu ${ }^{\oplus}$, Caiyun Wang ${ }^{\odot}$, \\ Xiuling $\mathrm{He}^{\oplus}$, Jinshan $\mathrm{Cao}^{\oplus}$ and Peifeng $\mathrm{Li}^{\odot *}$
}

Key Laboratory of Clinical Diagnosis and Treatment Techniques for Animal Disease, Ministry of Agriculture, College of Veterinary Medicine, Inner Mongolia Agricultural University, Hohhot, China

(Received July 24, 2017; Revised October 13, 2017; Accepted October 14, 2017)

\begin{abstract}
Taurochenodeoxycholic acid (TCDCA) is one of main bioactive substances of animals' bile acid and confers good anti-inflammatory activity. This study aimed to investigate the mechanism of the anti-adjuvant arthritis activity of TCDCA, the actions were observed in vitro on the protein and mRNA expression of cytokines, the activity of nuclear factor-kappa $\mathrm{B}(\mathrm{NF}-\kappa \mathrm{B})$ and its inhibitory $\mathrm{I} \kappa \mathrm{B} \alpha$ protein level of peritoneal macrophages (PMs) in adjuvant arthritis (AA) rats. In a definite concentration ranging from $150 \mu \mathrm{g} / \mathrm{mL}$ to 200 $\mu \mathrm{g} / \mathrm{mL}$, the over protein and mRNA expression of TNF- $\alpha$, IL- $1 \beta$ and IL-6 were remarkably suppressed in the supernatant of PMs treatment with TCDCA. Positive correlations were found between changes of NF- $\kappa \mathrm{B}$ activity and expression of TNF- $\alpha$, IL- $1 \beta$ and IL- 6 influenced by TCDCA. The activity of NF- $\kappa$ B was markedly inhibited and IкB $\alpha$ protein level was increased by TCDCA $(150 \mu \mathrm{g} / \mathrm{mL}, 180 \mu \mathrm{g} / \mathrm{mL}$ and $200 \mu \mathrm{g} / \mathrm{mL})$. TCDCA suppresses the protein and mRNA expression of TNF- $\alpha$, IL- $1 \beta$, and IL-6 by inhibiting the NF- $\kappa$ B binding activity, which is mediated through up-regulating the $\mathrm{I} \kappa \mathrm{B} \alpha$ expression of PMs in AA rats.
\end{abstract}

Keywords: Taurochenodeoxycholic acid; adjuvant arthritis; peritoneal macrophages; nuclear factor-kappa B; cytokines. (C) 2018 ACG Publications. All rights reserved.

\section{Introduction}

Bile acids are synthesized in the liver from oxidation of cholesterol and stored in the gallbladder as the main constituent of bile. Chenodeoxycholic acid (CDCA) and cholic acid (CA) are the two primary bile acids and are conjugated mainly to glycine (G) and taurine (T), which are taurochenodeoxycholic acid (TCDCA), glycocholic acid (GCA) and taurocholic acid (TCA) [1]. It is clear that bile acids not only facilitate digestion, absorption, and excretion of dietary lipids, but also bile acids interact with numerous cellular signaling pathways [2-5]. TCDCA is synthesized with taurine and chenodeoxychlolic acid in organism (Figure 1), which is one of main bioactive substances of bile from animal bile. In our previous study, TCDCA conferred remarkably inhibition on both acute and chronic inflammation, especially it favorably ameliorate the progression development and bone destruction of AA in rat [6].

\footnotetext{
* Corresponding author: E-mail: lpfneimeng2015@163.com; Phone: +86 04714314662 Fax: +86 04714314662.

$\S_{\text {These authors contributed equally to this work. }}$
} 


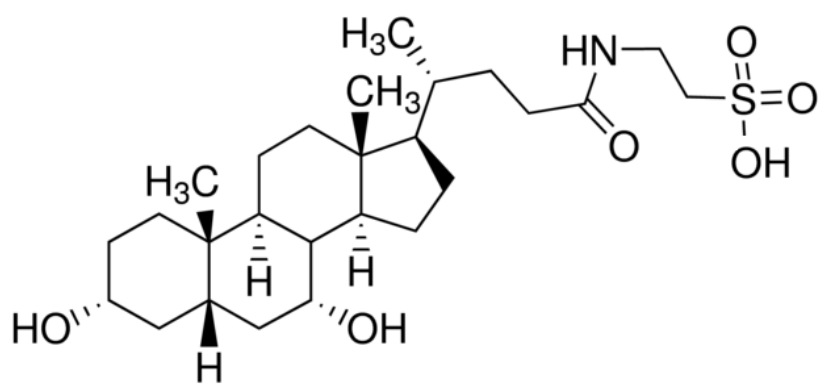

Figure 1. Chemical structure of TCDCA.

$\mathrm{NF}-\mathrm{kB}$ is one of most important transcription factors that plays pivotal role and was activated in regulation of inflammation in Rheumatoid arthritis (RA). The activation of NF- $\kappa B$ is required to induce expression of diverse inflammatory and immune response mediators. Once NF- $\mathrm{kB}$ was activated by a variety of pathogenic stimuli, comprehensive responses were induced, including overproduction of cytokines, such as TNF- $\alpha$, IL-1 $\beta$ and IL-6 [7], synoviocytes proliferation, activation of cyclooxygenase 2 and metallo-protease in RA [8,9].

Based on the good anti-adjuvant arthritis activity of TCDCA, we investigated whether TCDCA had directed pharmacologic action on the NF- $\mathrm{kB}$ activity and related cytokines expression in peritoneal macrophages from AA rats. The present study is undertaken to determine the NF- $\mathrm{BB}$ activity, I $\kappa \mathrm{B} \alpha$ protein level and the protein and mRNA expression of TNF- $\alpha$, IL-1ßand IL-6 in peritoneal macrophages.

\section{Materials and Methods}

\subsection{Reagents}

Freund's complete adjuvant (FCA) (Shanghai institute of biological products, China), ELISA kits of TNF- $\alpha$, IL-1 $\beta$ and IL-6 (R\&D systems, USA), Tripure ${ }^{\mathrm{TM}}$ RNA regent, M-MulV Reverse Transcripts and SYBR ${ }^{\circledR}$ PremixEx Tag $^{\mathrm{TM}}$ (TaKaRa Biotechnology, China), The antibodies again phosphorylated and non-phosphorylated IкB $\alpha$ (Cell Signaling Technology, USA), Nuclear Extract Kit and TransAM ${ }^{\circledR} \mathrm{NF}-\mathrm{kBp} 65$ kit (Active Motif, USA).

\subsection{TCDCA Dissociated and Depurated}

Fresh chicken gall was collected from chicken slaughterhouse, filtered by filter paper, deproteinated by alcohol, depigmented by activated carbon, condensed by rotary evaporator, salted out, extracted, dewatered, after that crude bile acid was obtained. TCDCA $(\mathrm{m} / \mathrm{z}: 499.69$; alpha,7- $\alpha-$ dihydroxy-5- $\beta$-24-alkylacyl-N-taurine, $\left.\mathrm{C}_{23}(\mathrm{OH})_{2} \mathrm{H}_{37} \mathrm{CONHCH}_{2} \mathrm{CH}_{2} \mathrm{SO}_{3} \mathrm{H}\right)$ was dissociated and depurated from crude bile acid by chromatography techniques and the purity was detected by high performance liquid chromatography and its purity was $>99.5 \%$.

\subsection{Animals and Induction of AA Rat}

The study was approved by Institute's Animal Ethical Committee (Approval ID: 20101027-3) and confirmed to national guidelines on the care and use of laboratory animals. Male wistar rats, 11 13 weeks old, weighing 160 180g, were obtained from experimental animal center, academy of military medical sciences in China. All animals were maintained at a controlled temperature $(22 \pm 2$ $\left.{ }^{\circ} \mathrm{C}\right)$, and a regular light/dark cycle (7:00 19:00 h, light), and all animals had free access to food and water. AA rat was induced as previously described [10]. Briefly, rats were immunized on day 0 by intradermal injection of FCA into the foot pad, containing $10 \mathrm{mg}$ heat-inactive Bacillus CalmetteGuerin in $1 \mathrm{ml}$ paraffin oil, into the left hind paw in $0.1 \mathrm{~mL}$ for each rat. 


\subsection{Isolation of Peritoneal Macrophages}

The peptone-elicited peritoneal-exudate cells were obtained from AA rats after they were given an intra-peritoneal injection of $1 \mathrm{ml} \mathrm{5 \%}$ peptone solution. 5\% Peptone solution followed by a lavage of the peritoneal cavity with $20 \mathrm{~mL}$ of medium 2 days later. The cells were washed twice and re-suspended in RPMI-1640 (GIBCO, Grand Island) containing 10\% heat-inactivated fetal bovine serum, penicillin $(100 \mathrm{IU} / \mathrm{mL})$ and streptomycin $(100 \mu \mathrm{g} / \mathrm{mL})$. The macrophages were isolated from the peritoneal exudate cells using the method described by Um et al [11]. The peritoneal exudate cells were seeded on teflon-coated petri dishes and the macrophages were allowed to adhere for $4 \mathrm{~h}$ at $37^{\circ} \mathrm{C}$ in a $5 \% \mathrm{CO}_{2}$ humidified atmosphere. Non-adherent cells were removed by washing the dishes twice with prewarmed medium and new medium was added into the plate containing TCDCA at different concentrations.

\subsection{Peritoneal Macrophages Proliferation Assay}

Peritoneal macrophages were seeded at a concentration of $1 \times 10^{5}$ cells/well in 96 -well culture plates and incubated at $37^{\circ} \mathrm{C}, 5 \% \mathrm{CO} 2$ for $4 \mathrm{~h}$. After the cells adhere, the cultures were replaced by new RPMI-1640 with different concentrations of TCDCA (concentration ranging from $0 \mu \mathrm{g} / \mathrm{mL}$ to 300 $\mu \mathrm{g} / \mathrm{mL}$ ). The absorbance (OD value) was measured at $24 \mathrm{~h}$ by MTT ((3-(4,5-dimethylthiazol-2-yl)2,5-diphenyl-tetrazolium bromide)) method after incubation [12].

\subsection{Preparation of Peritoneal Macrophages Supernatants and Total RNA}

Obtained peritoneal macrophages were resuspended in RPMI-1640 medium at a concentration of $5 \times 10^{6}$ cells $/ \mathrm{mL}$ and were added to six-well culture plate (final volume was $3 \mathrm{~mL} / \mathrm{well}$ ). After the cells adhere for $4 \mathrm{~h}$, new RPMI-1640 medium with different concentration of TCDCA and LPS (5 $\mu \mathrm{g} / \mathrm{mL}$ ) were added to culture plate. Cells were randomly divided into five groups: Normal group (normal rat cells), AA group (AA rat cells without TCDCA), the remaining three TCDCA groups were treated with different concentrations of TCDCA $(150 \mu \mathrm{g} / \mathrm{mL}, 180 \mu \mathrm{g} / \mathrm{mL}, 200 \mu \mathrm{g} / \mathrm{mL})$. Culture supernatants were collected and total RNA were isolated using Trizol from peritoneal macrophages after incubation with TCDCA for $24 \mathrm{~h}$.

\subsection{Measurement of Related Cytokines Concentration in the Supernatant of Peritoneal Macrophages}

The concentrations of TNF- $\alpha$, IL- $1 \beta$ and IL- 6 in the supernatant of peritoneal macrophages were measured by ELISA according to the manufacturer instructions at $24 \mathrm{~h}$ post treatment. The analytic sensitivity for these assays were $5 \mathrm{pg} / \mathrm{mL}$ (TNF- $\alpha$ ), $5 \mathrm{pg} / \mathrm{mL}$ (IL-1 $\beta$ ) and $6 \mathrm{pg} / \mathrm{mL}$ (IL-6).

\subsection{Relative mRNA Expression of Related Cytokines in Peritoneal Macrophages}

Peritoneal macrophages were collected and kept at $-80{ }^{\circ} \mathrm{C}$ until RNA extraction. Total cellular RNA was extracted using Tripure ${ }^{\mathrm{TM}}$ RNA reagent. Synthesis of cDNA was performed using an MMulV Reverse Transcriptase with random 9-mers according to the manufacturer's protocol. cDNA was amplified using SYBR ${ }^{\mathbb{B}}$ Premix Ex TagTM (Perfect Real time) kit with specific oligonucleotide primers for target sequences of and in a total of $25 \mu \mathrm{L}$ reaction mixture $(2 \mu \mathrm{L}$ of cDNA, $12.5 \mu \mathrm{L}$ of $2 \times \mathrm{SYBR}^{\circledR}$ Premix Ex TagTM, $2 \mu \mathrm{L}$ of each $10 \mu \mathrm{M}$ forward and reverse primers and $8.5 \mu \mathrm{L}$ of $\mathrm{H}_{2} \mathrm{O}$ ). The real-time quantitative PCR thermal cycling conditions were $95^{\circ} \mathrm{C}$ for $30 \mathrm{~s}$, followed by $95^{\circ} \mathrm{C}$ for $5 \mathrm{~s}$ and $\mathrm{Tm}$ for $30 \mathrm{~s}$ for 35 cycles. The primer sequences and Tm were shown in Table1. All primers were synthesized by TaKaRa Biotechnology (China). Data were analyzed according to the comparative Ct method [9] and were normalized by $\beta$-actin expression in each sample. Relative mRNA levels were calculated based on the $\mathrm{Ct}$ values, corrected for $\beta$-actin expression, according to the equation: $2^{-\triangle \mathrm{Ct}}[\triangle \mathrm{Ct}=\mathrm{Ct}(\operatorname{target})-\mathrm{Ct}(\beta$-actin $)]$. Melting curves for each PCR reaction were generated to ensure the purity of the amplification product. 
Table 1. Primer, temperature and amplified products size and reference in this study

\begin{tabular}{|c|c|c|c|}
\hline Primer & Temperature & Amplified products size & Sequence \\
\hline$\beta$-Actin & $60.0^{\circ} \mathrm{C}$ & $150 \mathrm{bp}$ & $\begin{array}{l}\text { Sense:5'-CCC ATC TAT GAG GGT TAC GC-3' } \\
\text { htisense:5'-TTT AAT GTC ACG C AC GAT TTC-3' }\end{array}$ \\
\hline TNF- $\alpha$ & $58.2^{\circ} \mathrm{C}$ & $360 \mathrm{bp}$ & $\begin{array}{l}\text { Sense: 5'-ACC CCC AAC CTA TGA AGA AA-3', } \\
\text { ntisense: 5'-TCC ACG CAAAAC GGA ATG AA-3' }\end{array}$ \\
\hline IL-1 $\beta$ & $56.5^{\circ} \mathrm{C}$ & $377 \mathrm{bp}$ & $\begin{array}{l}\text { Sense: 5'TTG TGG CTG TGG AGA AGC TG-3' } \\
\text { Antisense: 5'-GCC GTC TTT CAT ACA CAG G' }\end{array}$ \\
\hline IL-6 & $59.8^{\circ} \mathrm{C}$ & $210 \mathrm{bp}$ & $\begin{array}{l}\text { Sense: 5' -TAG AGT CAC AGA AGG AGT GG-3' } \\
\text { Antisense: 5' -GCC AGT TCT TCG TAG AGA -3' }\end{array}$ \\
\hline
\end{tabular}

\subsection{DNA-binding Activity of NF- $\kappa B p 65$}

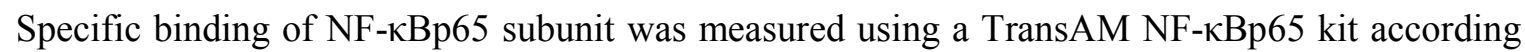
to the manufacturer's instructions. After treatment with TCDCA, cells were collected by scraping and centrifugation. Cell nuclear extracts were then added into a 96-well plate immobilized with oligonucleotide containing the NF- $\mathrm{KB}$ consensus site (5'-GGG ACT TTC C-3'). Using a primary antibody directed against the NF- $\mathrm{kBp} 65$ subunit and a second antibody conjugated to horseradish peroxidase, the optical density was qualified by spectrophotometry using Bio-Tek ELX-800 ELIASA (USA).

\subsection{Western Blot Analysis}

After treatment with TCDCA for $24 \mathrm{~h}$, PMs were washed twice with ice-cold PBS. The cells were lysed with lysis buffer (50mM Tris-Cl [pH 8.0], $150 \mathrm{mM} \mathrm{NaCl}, 0.02 \% \mathrm{NaN} 3$, and $1 \% \mathrm{NP} 40)$. The cytosolic fraction was obtained from the supernatant after $12,000 \mathrm{rpm}$ centrifugation at $4{ }^{\circ} \mathrm{C}$ for 15 min. Samples $(20 \mathrm{mg}$ of protein) were separated on a $10 \%$ SDS-PAGE and transferred to nitrocellulose membranes. The membranes were blocked with $5 \%$ nonfat milk in PBS-Tween $(0.1 \%$, PBST) for $1 \mathrm{~h}$, and then incubated with monoclonal antibodies against rat IKB $\alpha$, and phosphorylated$\mathrm{I} \kappa \mathrm{B} \alpha(\mathrm{p}-\mathrm{I} \kappa \mathrm{B} \alpha)$ in PBST containing $1 \%$ nonfat milk for $1 \mathrm{~h}$. After washing three times with PBST, the membrane was hybridized with secondary antibody conjugated to horseradish peroxidase for $1 \mathrm{~h}$ and washed three times with PBST. The membrane was incubated with ECL reagent for $2 \mathrm{~min}$ and exposed to X-ray film [13].

\subsection{Statistical Analysis}

Statistical analysis was performed using SPSS 16.0 software. Significance of the differences between controls and experimental groups was determined by one-way ANOVA analysis. $P<0.05$ was considered significant.

\section{Results and Discussion}

\subsection{Induction of AA rat}

All rats developed severe inflammation, and typically non-injected hind limb became severely red and edematous on days 13 after were injected with FCA. Involvement was predominantly distal with ankle, tarsal and inter phalangeal inflammation and few nodules in the tail. Peak severity occurred within 13 15 days after the onset with each involved limb usually reaching a maximum score by the arthritic index (Figure 2). 


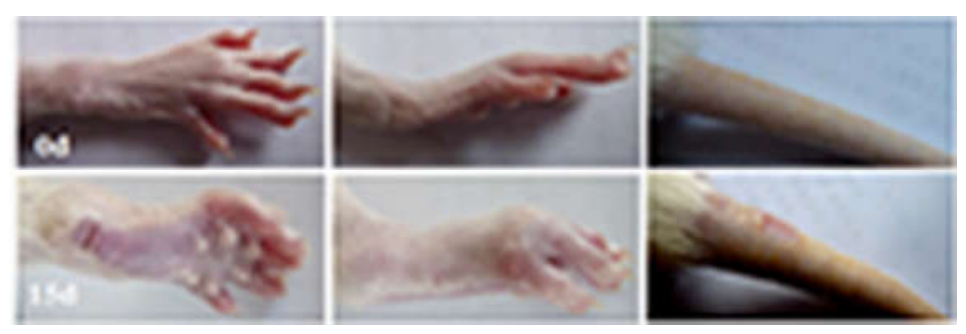

Figure 2. The changes of right paw and tail of one rat within 15 days after immunization. Compared to the normal rat, there were severely red and edematous swelling of paw and apparent nodules in the tail on days 15 after immunization.

\subsection{Effects of TCDCA on Peritoneal Macrophages Proliferation}

With the concentration ranging from $0 \mu \mathrm{g} / \mathrm{mL}$ to $200 \mu \mathrm{g} / \mathrm{mL}$, TCDCA showed no toxicity on the peritoneal macrophages proliferation at $24 \mathrm{~h}$ post treatment. From $200 \mu \mathrm{g} / \mathrm{mL}$ to $300 \mu \mathrm{g} / \mathrm{mL}$, TCDCA appeared markedly progressing inhibition, respectively (Figure 3). Based on this results, the concentration of TCDCA $150 \mu \mathrm{g} / \mathrm{mL}, 180 \mu \mathrm{g} / \mathrm{mL}$ and $200 \mu \mathrm{g} / \mathrm{mL}$ was used in our further experiments.

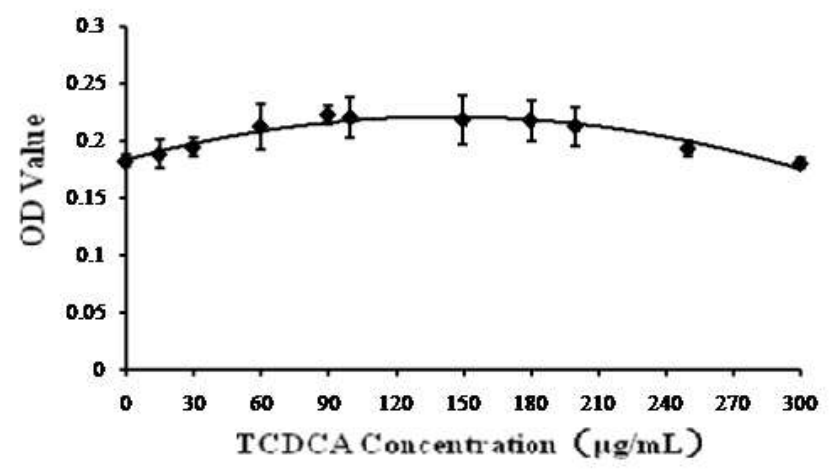

Figure 3. Effects of TCDCA on peritoneal macrophages proliferation of AA rats. In a define concentration ranging from $0 \mu \mathrm{g} / \mathrm{mL}$ to $300 \mu \mathrm{g} / \mathrm{mL}$, effects of TCDCA on peritoneal macrophages proliferation were detected by MTT method. With the concentration ranging from $0 \mu \mathrm{g} / \mathrm{mL}$ to 100 $\mu \mathrm{g} / \mathrm{mL}$, TCDCA showed promoting action, and from $100 \mu \mathrm{g} / \mathrm{mL}$ to $300 \mu \mathrm{g} / \mathrm{mL}$, TCDCA appeared markedly progressing inhibition. Data are expressed as mean $\pm \mathrm{S} . \mathrm{D}(\mathrm{n}=5) . * P<0.05, * * P<0.01$ vs. the OD value of peritoneal macrophages without TCDCA.

\subsection{Effects of TCDCA on Related Cytokines Production}

The concentration of TNF- $\alpha$, IL- $1 \beta$ and IL- 6 were markedly increased in the peritoneal macrophages from AA rats compare to normal rats. TNF- $\alpha$, IL- $1 \beta$ and IL- 6 production were markedly decreased by TCDCA $(150 \mu \mathrm{g} / \mathrm{mL}, 180 \mu \mathrm{g} / \mathrm{mL}$ and $200 \mu \mathrm{g} / \mathrm{mL})$ on a concentration-dependent manner (Figure 4). 

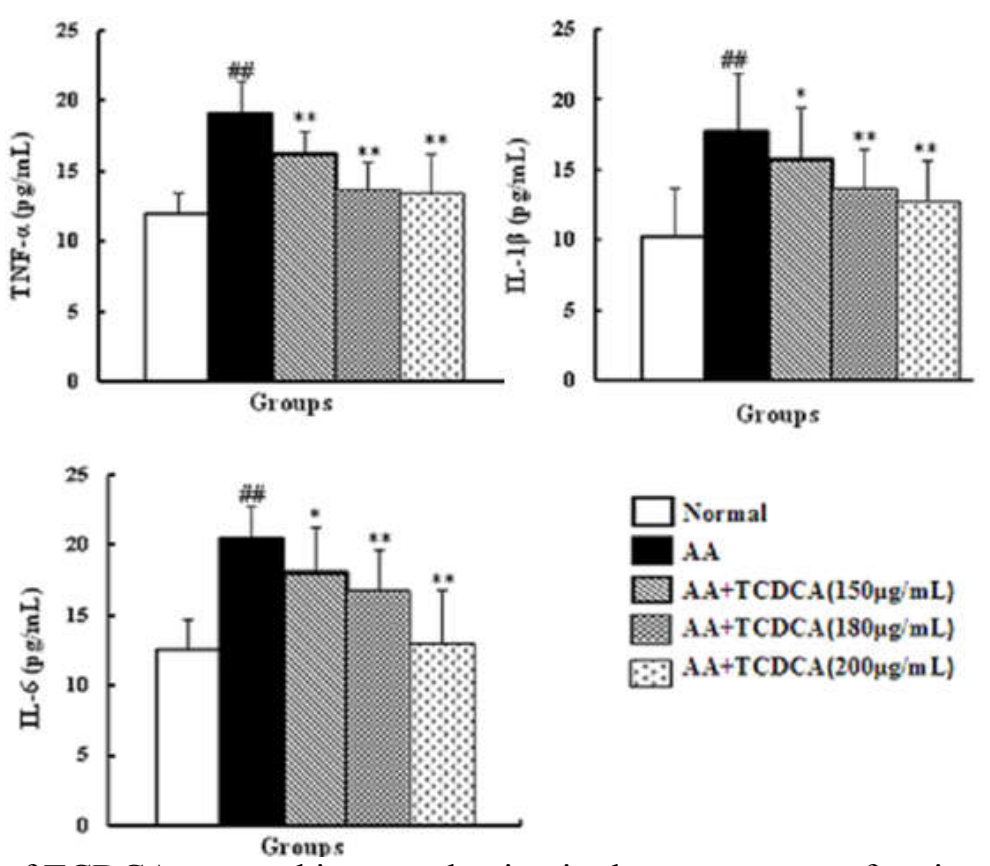

Figure 4. Effects of TCDCA on cytokines production in the supernatant of peritoneal macrophages. TNF- $\alpha$, IL-1 $\beta$, IL- 6 and IL-10 content were detected by ELISA in the supernatant. The concentration of TNF- $\alpha$, IL- $1 \beta$ and IL- 6 were significant higher in peritoneal macrophages of AA rat than of normal rat. Overproduction of TNF- $\alpha$, IL-1 $\beta$ and IL- 6 were inhibited by TCDCA (from $100 \mu \mathrm{g} / \mathrm{mL}$ to 300 $\mu \mathrm{g} / \mathrm{mL})$. Data are expressed as mean \pm S.D $(\mathrm{n}=8) .{ }^{\#} p<0.05,{ }^{\#} p<0.01$ vs normal peritoneal macrophages; $* p<0.05,{ }^{*} p<0.01$ vs. AA peritoneal macrophages.

\subsection{Effects of TCDCA on Related Cytokines mRNA Expression}

mRNA expression levels of TNF- $\alpha$, IL- $1 \beta$ and IL- 6 were markedly increased in the peritoneal macrophages was seen from AA rats compare to normal rats. mRNA expression levels of TNF- $\alpha$, IL$1 \beta$ and IL-6 were markedly inhibited by TCDCA $(150 \mu \mathrm{g} / \mathrm{mL}, 180 \mu \mathrm{g} / \mathrm{mL}$ and $200 \mu \mathrm{g} / \mathrm{mL})$ (Figure 5).
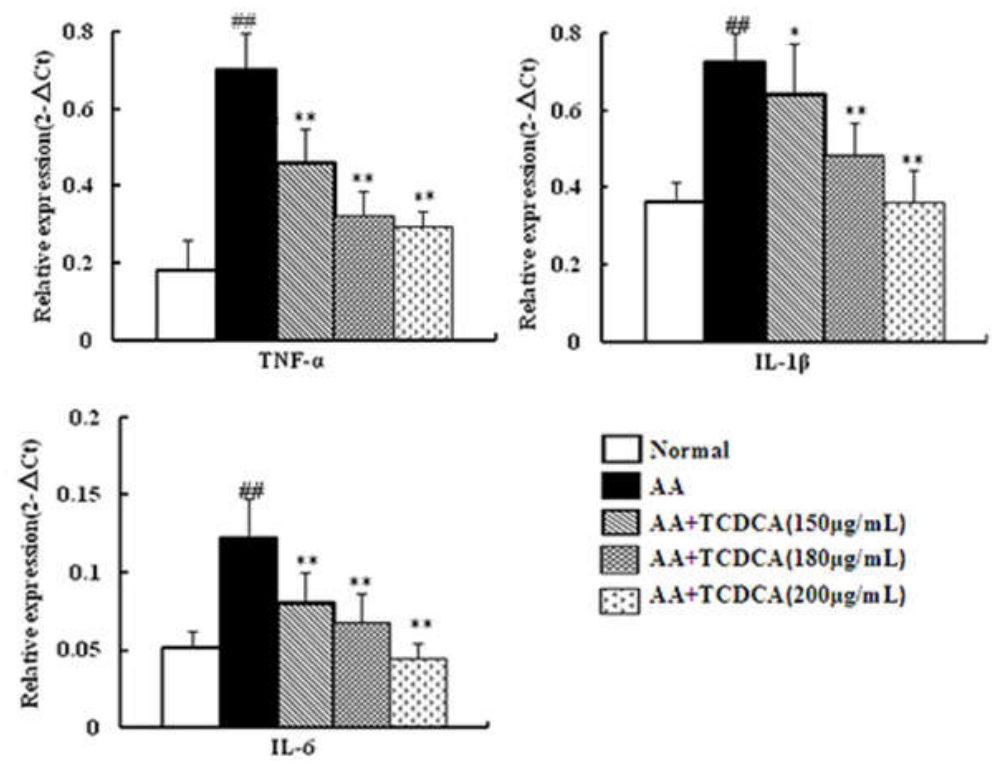

Figure 5. Effects of TCDCA on related cytokines mRNA expression in peritoneal macrophages of AA rats. mRNA expression levels of related cytokines were determined by real time RT-PCR in peritoneal macrophages. mRNA expression levels of TNF- $\alpha$, IL-1 $\beta$ and IL- 6 were markedly inhibited by TCDCA $(150 \mu \mathrm{g} / \mathrm{mL}, 180 \mu \mathrm{g} / \mathrm{mL}$ and $200 \mu \mathrm{g} / \mathrm{mL})$. Data are expressed as mean \pm S.D $(\mathrm{n}=8)$. ${ }^{\#} p<0.05,{ }^{\#} p<0.01$ vs normal synoviocytes; ${ }^{*} \mathrm{p}<0.05,{ }^{* *} p<0.01$ vs AA synoviocytes. 


\subsection{Effects of TCDCA on DNA-binding Activity of NF- $\kappa B p 65$}

DNA-binding activity of the NF- $\kappa B$ p65 subunit was evaluated using a sensitive multi-well colorimetric assay. Cells were pretreated with TCDCA for $24 \mathrm{~h}$. It showed that 2.35-fold-enhanced DNA-binding capacity in the peritoneal macrophages from AA rats compare to normal rats. Cells treated with TCDCA showed weaker NF-kBp65 activity with different concentration and statistical significance was detected compare to cells without treatment of TCDCA (Figure 6).

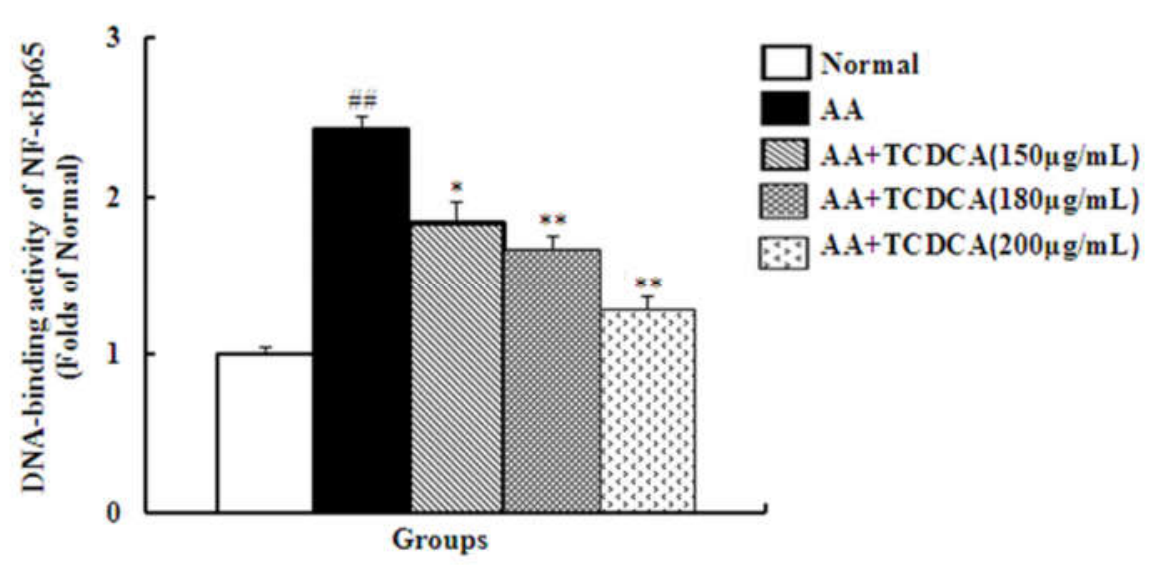

Figure 6. Effects of TCDCA on DNA-binding activity of NF- $\kappa B p 65$ in peritoneal macrophages of AA rats. DNA-binding activity of the NF- $\mathrm{kB}$ p65 subunit was evaluated using a sensitive multiwell colorimetric assay. Activity of the NF- $\kappa B$ p65 was inhibited by treatment with TCDCA $(150 \mu \mathrm{g} / \mathrm{mL}$, $180 \mu \mathrm{g} / \mathrm{mL}$ and $200 \mu \mathrm{g} / \mathrm{mL}$ ), and statistical significance was detected compare to cells without TCDCA. Data are expressed as mean \pm S.D $(\mathrm{n}=8) .{ }^{\#} p<0.05,{ }^{\#} p<0.01$ vs normal peritoneal macrophages; ${ }^{*} p<0.05,{ }^{*} p<0.01$ vs AA peritoneal macrophages.

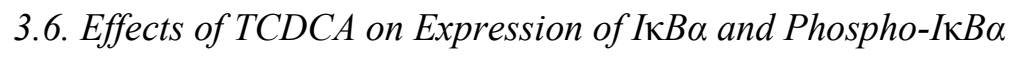

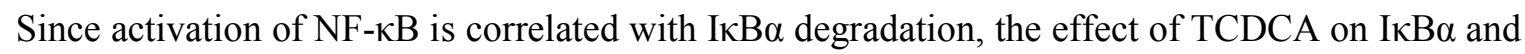
phospho-I $\kappa \mathrm{B} \alpha$ expression was examined to clarify the inhibitory action of TCDCA (Figure 7). It

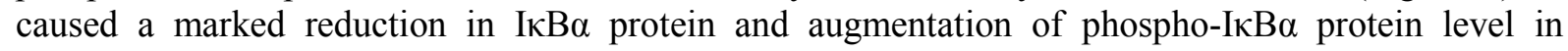
peritoneal macrophages from AA rats. Treatment of TCDCA with different concentration resulted in marked augmentation of I $\mathrm{B} \alpha$ protein and reduction of phospho-I $\mathrm{B} \alpha$ protein level in the cytoplasmic fractions of peritoneal macrophages.

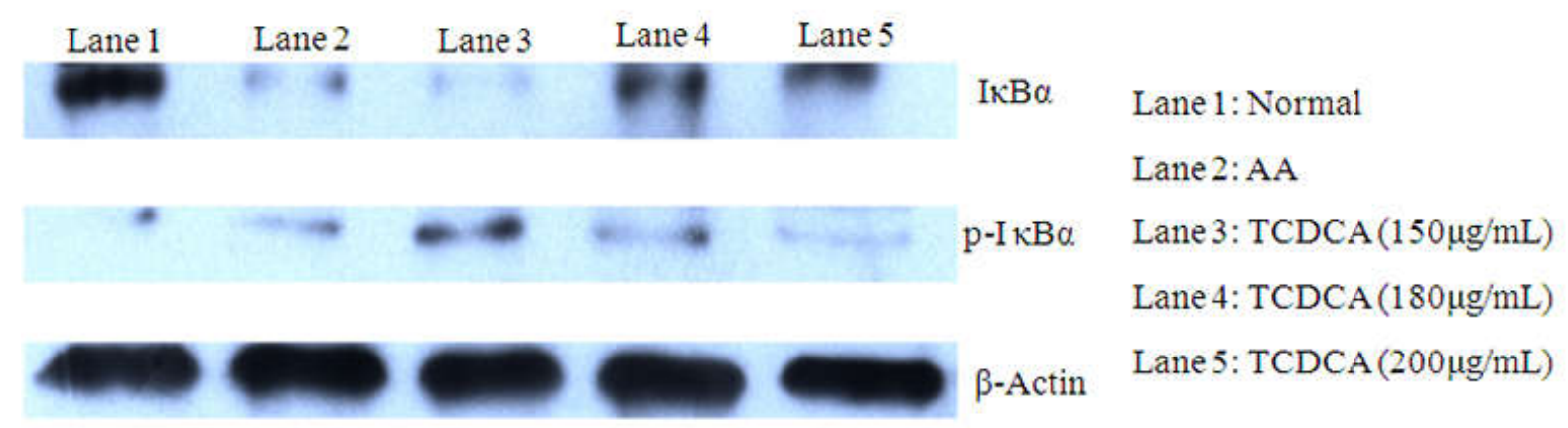

Figure 7. Effects of TCDCA on expression of $I \kappa B \alpha$ and phospho-I $\kappa \mathrm{B} \alpha$ in peritoneal macrophages of

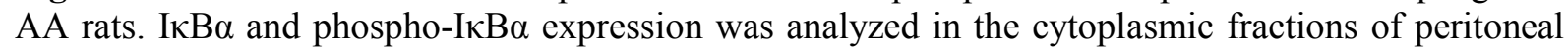
macrophages by western-blot. Treatment with TCDCA caused a marked augmentation in IкB $\alpha$ protein and reduction of phospho-IкB $\alpha$ protein level in the peritoneal macrophages from AA rats. 
RA is a chronic autoimmune disease associated with multiple inflammatory mediators that lead to joint damage, synovial inflammation and cartilage and bone damage [14,15]. Nowadays, there is dramatically growing interest in herbal medicines among persons with RA and in RA research community. In fact, herbal medicine is being widely used virtually around the world for treatment of rheumatic and arthritic diseases and in recent year, considerable advances have been made in both clinical and basic research on the treatment of RA. As one kind of natural bioactive substance of animal bile acid dissociated and depurated from chicken bile, TCDCA showed noticeable antiinflammatory and immuno-regulation roles in both acute and chronic inflammation. In our previous study, it was proved that TCDCA conferred a good anti-adjuvant arthritis activity in rats and inhibited the expression of inflammatory cytokines in the synoviocytes [16]. However, the action of TCDCA, on the NF- $\mathrm{kB}$ and related cytokines expression in peritoneal macrophages, was unknown.

One of the most widely used models for studying the anti-inflammatory, anti- rheumatic properties of compounds is adjuvant-induced arthritis in rats. It is an experimental immunopathy and to be considered to share many features with human rheumatoid arthritis. In this model, arthritis develops within 2 weeks and is characterized by developed severe inflammation, and typically noninjected hind limb became severely red and edematous, and few nodules in the tail (Figure 2).

Macrophages and synoviocytes, in particular, are the most vigorous producers of intercellular mediators in RA. Peritoneal macrophages can be stimulated by a variety of agents such as IFN- $\gamma$, lipopolysaccharides, or other microbial products [17-19] and some of these have also been shown to trigger the release of TNF- $\alpha$, IL-1 $\beta$ and IL- 6 by the macrophages [20-23]. Peritoneal macrophages proliferation result showed that from $100 \mu \mathrm{g} / \mathrm{mL}$ to $300 \mu \mathrm{g} / \mathrm{mL}$, TCDCA appeared markedly progressing inhibition, and its inhibited rates reached to $10 \%, 20 \%$ and $30 \%$ in the concentration of TCDCA $150 \mu \mathrm{g} / \mathrm{mL}, 180 \mu \mathrm{g} / \mathrm{mLand} 200 \mu \mathrm{g} / \mathrm{mL}$, respectively (Figure 3).

Modulation of NF- $\mathrm{kB}$ activation could be an important strategy to reduce cellular injury. There is in fact increasing evidence to suggest that NF- $\mathrm{BB}$ is an important mediator in the pathophysiology of diseases characterized by elevated levels of cytokines such as sepsis and inflammation $[24,25]$. Our data demonstrate for the first time that TCDCA has the ability to block induced activation of NF- $\mathrm{KB}$ in peritoneal macrophages from AA rats. NF- $\mathrm{KB}$ activity was effectively suppressed during TCDCA incubation on a concentration-dependent manner (from $150 \mu \mathrm{g} / \mathrm{mL}$ to 200 $\mu \mathrm{g} / \mathrm{mL}$ ) (Figure 6).

Accordingly, an NF- $\kappa \mathrm{B}$ inhibitory protein known as $\mathrm{I} \kappa \mathrm{B} \alpha$, its protein expression was marked increased and phospho-I $\mathrm{B} \alpha$ protein expression was marked decreased by TCDCA $(150 \mu \mathrm{g} / \mathrm{mL}, 180$ $\mu \mathrm{g} / \mathrm{mL}$ and $200 \mu \mathrm{g} / \mathrm{mL}$ ) as shown in Figure 7. The present data demonstrate that it induced a

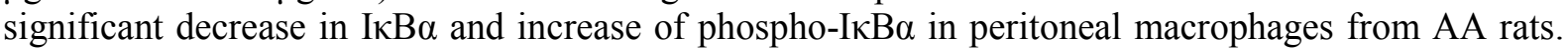
TCDCA inhibited I $\mathrm{\kappa} B \alpha$ degradation and decreased the expression levels of phospho-IkB $\alpha$ with different concentration on a concentration-dependent manner, and thereby blocked NF- $\mathrm{BB}$ translocation to the nucleus. Thus, this mechanism appears to be involved in the action of antiadjuvant arthritis activity.

$\mathrm{NF}-\mathrm{\kappa B}$ is a ubiquitous transcription factor that plays a key role in the expression of many genes central to RA, including IL-1 $\beta$ in monocytes, as well as intercellular adhesion molecule-1 (ICAM-1), TNF- $\alpha$ and IL-6 [26-28]. The present study indicated that additional treatment with TCDCA reduced the elevated binding activity on a concentration-dependent manner (Figure 6). Furthermore, positive correlations were found between changes of NF- $\mathrm{kB}$ and the mRNA and secretion of TNF- $\alpha$, IL- $1 \beta$ and IL- 6 treatment with TCDCA. Over production of TNF- $\alpha$, IL- $1 \beta$ and IL6 was markedly decreased by treatment with TCDCA $(150 \mu \mathrm{g} / \mathrm{mL}, 180 \mu \mathrm{g} / \mathrm{mL}$ and $200 \mu \mathrm{g} / \mathrm{mL})$ on a concentration-dependent manner, in contrast (Figure 4). mRNA expression levels of TNF- $\alpha$, IL-1 $\beta$ and IL-6 were markedly inhibited by TCDCA $(150 \mu \mathrm{g} / \mathrm{mL}, 180 \mu \mathrm{g} / \mathrm{mL}$ and $200 \mu \mathrm{g} / \mathrm{mL})$ (Figure 5).

These results demonstrated that TCDCA decreases the mRNA expression and secretion of TNF- $\alpha$, IL-1 $\beta$ and IL- 6 by inhibiting the NF- $\kappa B$ binding activity. Accordingly, NF- $\kappa B$ might be the upstream mechanism of the inhibitory effect of TCDCA on AA-induced TNF- $\alpha$, IL- $1 \beta$ and IL- 6 expressions. This could also explain the anti-RA role of TCDCA, because NF- $\kappa B$ acts as an important transcriptional factor in the pathogenesis of RA 


\section{Conclusion}

In this study, TCDCA reduces the pro-inflammatory cytokines, TNF- $\alpha$, IL-1 $\beta$ and IL- 6 production in PMs from AA rats at transcriptional level by inhibiting NF- $\kappa B$ activity, and the inhibitory effect of $\mathrm{NF}-\kappa \mathrm{B}$ activity is mediated through up-regulating the IкB $\alpha$ expression, which might be one of the antiadjuvant arthritis activity mechanisms of TCDCA.

\section{Acknowledgment}

This study was supported by National Science Foundation of China (No. C30860210, No. C31160518, No. 31402248 and No. 31272605).

Competing interests: None of the authors of this paper has a financial or personal relationship with other people or organizations that could inappropriately influence or bias the content of the paper. The authors declare that they have no competing interests.

Ethics approval and consent to participate: The study was approved by the farm owner and all animal experiments were conducted according to the International Guiding Principles for Biomedical Research. The protocol was approved by the Committee on the Ethics of Animal Experiments of the Inner Mongolia Agricultural University (Approval ID: 20101027-3).

\section{ORCID}

Wei Mao: 0000-0002-4198-9324

Mingqiang Liu: 0000-0001-7432-4831

Hong Guan: 0000-0002-9192-4457

Bo Liu: 0000-0003-3187-7879

Caiyun Wang: 0000-0002-2974-6151

Xiuling He: 0000-0003-2305-5955

Jinshan Cao: 0000-0002-3644-5082

Peifeng Li: $0000-0003-2455-6102$

\section{References}

[1] A.F. Hofmann (2009). Bile Acids: Trying to understand their chemistry and biology with the hope of helping patients, Hepatology 49, 1403-1418.

[2] A. Nguyen and B. Bouscarel (2008). Bile acids and signal transduction: Role in glucose homeostasis. Cellular Signall. 20, 2180-2197.

[3] B. Bouscarel, S.D. Kroll and H. Fromm (1999). Signal transduction and hepatocellular bile acid transport: Cross talk between bile acids and second messengers, Gastroenterology 117, 433-52.

[4] C.A. Argmann, S.M. Houten, M.F. Champy and J. Auwerx (2006). Lipid and bile acid analysis, Current Protocols in Molecular Biology / Edited by Frederick M. Ausube, Chapter 29, Unit 29B.2.

[5] F. Hirano, M. Haneda and I. Makino (2006). Chenodeoxycholic acid and taurochenodexycholic acid induce anti-apoptotic cIAP-1 expression in human hepatocytes, J. Gastroenterol. Hepatol. 21, 18071813.

[6] L. Li, C. Liu, M. Liu, L. Shi, Q. Liu, H. Guan and P. Li (2013). Taurochenodeoxy cholicacid induces apoptosis of fibroblast-likesynoviocytes, Eur. J. Pharmacol. 706,36-40.

[7] Y.H. Wei, Y. Li and C.J. Qiang (2004). Effects and mechanisms of FR167653, a dual inhibitor of interleukin-1 and tumor necrosis factor, on adjuvant arthritis in rats, Int. Immunopharmacol. 4, 16251632.

[8] S.S. Makarov (2001). NF-kappa B in rheumatoid arthritis: A pivotal regulator of inflammation, hyperplasia, and tissue destruction, Arthritis Res. 3, 200-206.

[9] W. Liu, G. Xu, J. Ma, W. Jia, J. Li, K. Chen, W. Wang, C. Hao, Y. Wang and X. Wang (2011). Osteopontin as a key mediator for vasculogenic mimicry in hepatocellular carcinoma, Tohoku J. Exp. 
Med. 224, 29-39.

[10] K.S. Kim, Y.H. Choi, K.H. Kim, Y.C. Lee, C.H. Kim, S.H. Moon, S.G. Kang and Y.G. Park (2004). Protective and anti-arthritic effects of deer antler aqua-acupuncture (DAA), inhibiting dihydroorotate dehydrogenase, on phosphate ions-mediated chondrocyte apoptosis and rat collagen-induced arthritis, Int. Immunopharmacol. 4, 963-973.

[11] S.H. Um, D.K. Rhee and S. Pyo (2002). Involvement of protein kinase C and tyrosin kinase in tumoricidal activation of macrophage induced by Streptococcus pneumoniae type II capsular polysaccharide, Int. Immunopharmacol. 2, 129-137.

[12] M. Theiszova, S. Jantova, J. Dragunova, P. Grznarova and M. Palou (2005). Comparison the cytotoxicity of hydroxyapatite measured by direct cell counting and MTT test in murine fibroblast NIH3 T3 cells, Biomed. Papers Med. Faculty Uni. Palacky, Olomouc, Czechoslovakia 149, 393-396.

[13] J. Martini, P. Cabrales, K. Ananda, S.A. Acharya, M. Intaglietta and A.G. Tsai. (2008). Survival time in severe hemorrhagic shock after perioperative hemodilution is longer with PEG-conjugated human serum albumin than with HES 130/0.4: a microvascular perspective, Critical Care. 12, R54.

[14] Y. Ono, M. Inoue, H. Mizukami and Y. Ogihara (2004). Suppressive effect of Kanzo-bushi-to, a Kampo medicine, on collagen-induced arthritis, Biol.Pharmaceut. Bull. 27, 1406-1413.

[15] S.J. Suh, K.S. Kim, S.D. Lee, C.H. Lee, H.S. Choi, U.H. Jin, Y.C. Chang and C.H. Kim (2006). Effects and mechanisms of Clematis mandshurica Maxim. as a dual inhibitor of proinflammatory cytokines on adjuvant arthritis in rats, Env. Toxicol. Pharmacol. 22, 205-212.

[16] M. Liu, W. Mao, H. Guan, L. Li, B. Wei and P. Li (2011). Effects of taurochenodeoxycholic acid on adjuvant arthritis in rats. Int Immunopharmacol.11, 2150-2158.

[17] M.R. Bernsen, A.V. van Der Velden, L.A. Everse, H.F. Dullens, W. Den Otter and A.P. Heintz (1998). Interleukin-2: hope in cases of cisplatin-resistant tumours, Cancer Immunol. Immunother. : CII .46, 4147.

[18] S. Gautam and S. Deodhar (1989). Generation of tumoricidal effector cells by human C-reactive protein and muramyl tripeptide: A comparative study, J. Biol. Response Modif. 8, 560-569.

[19] D.M. Paulnock and L.E. Lambert (1990). Identification and characterization of monoclonal antibodies specific for macrophages at intermediate stages in the tumoricidal activation pathway, J. Immunol. 144, 765-773.

[20] F. Arenzana-Seisdedos and J.L. Virelizier (1983). Interferons as macrophage-activating factors. II. Enhanced secretion of interleukin 1 by lipopolysaccharide-stimulated human monocytes, Eur. J. Immunol, 13, 437-440.

[21] M. Chokri, M. Freudenberg, C. Galanos, P. Poindron and J. Bartholeyns (1989). Antitumoral effects of lipopolysaccharides, tumor necrosis factor, interferon and activated macrophages: Synergism and tissue distribution, Anticancer Res. 9, 1185-1190.

[22] D.J. Stuehr and M.A. Marletta (1987). Synthesis of nitrite and nitrate in murine macrophage cell lines, Cancer Res. 47, 5590-5594.

[23] R. Keller, R. Keist and K. Frei (1990). Lymphokines and bacteria, that induce tumoricidal activity, trigger a different secretory response in macrophages, Eur. J. Immunol. 20, 695-698.

[24] S.F. Liu and A.B. Malik (2006). NF-kappa B activation as a pathological mechanism of septic shock and inflammation, Am. J. Physiol. Lung Cellu.Molec. Physiol. 290, L622-L645.

[25] H. Xu, Y. He, X. Yang, L. Liang, Z. Zhan, Y. Ye, X. Yang, F. Lian and L. Sun (2007). Anti-malarial agent artesunate inhibits TNF-alpha-induced production of proinflammatory cytokines via inhibition of NF-kappa B and PI3 kinase/Akt signal pathway in human rheumatoid arthritis fibroblast-like synoviocytes, Rheumatology 46, 920-926.

[26] K. Fujisawa, H. Aono, T. Hasunuma, K. Yamamoto, S. Mita and K. Nishioka (1996). Activation of transcription factor NF-kappa B in human synovial cells in response to tumor necrosis factor alpha, Arthrit. Rheumatism 39, 197-203.

[27] X. Cai, H. Zhou, Y.F. Wong, Y. Xie, Z.Q. Liu, Z.H. Jiang, Z.X. Bian, H.X. Xu and L. Liu (2007). Suppression of the onset and progression of collagen-induced arthritis in rats by QFGJS, a preparation from an anti-arthritic Chinese herbal formula, J. Ethnopharmacol. 110, 39-48.

[28] A.M. Agha and M. Mansour (2000). Effects of captopril on interleukin-6, leukotriene B(4), and oxidative stress markers in serum and inflammatory exudate of arthritic rats: evidence of antiinflammatory activity, Toxicol. Applied Pharmacol. 168, 123-130.

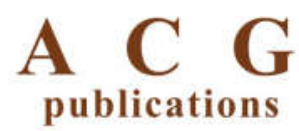

(C) 2018 ACG Publications 